\title{
The association of family history of prostate cancer with the diagnosis of clinically significant prostate cancer in Korean population
}

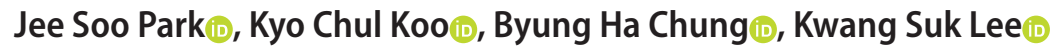 \\ Department of Urology, Yonsei University College of Medicine, Seoul, Korea
}

Purpose: The impact of family history on the diagnosis of the prostate cancer among Asian population remains controversial. We evaluated whether a positive family history of the prostate cancer in Korean men is associated with the diagnosis and aggressiveness of the prostate cancer.

Materials and Methods: Patients who underwent a transrectal ultrasound-guided prostate biopsy from March 2015 to September 2017 were evaluated. Information on family history was obtained via a self-administered questionnaire. The presence of prostate cancer and clinically significant prostate cancer (Gleason score $\geq 7$ ) was evaluated according to the presence of a family history.

Results: Of 602 patients (median age, 68.3 years; median prostate-specific antigen level, $6.28 \mathrm{ng} / \mathrm{mL}$ ), 41 (6.8\%) patients had a family history of prostate cancer. Family history was a significant factor for detecting prostate cancer (odds ratio [OR], 2.99; 95\% confidence interval $[\mathrm{Cl}], 1.330-6.704 ; \mathrm{p}=0.008)$. In multivariate analysis for predicting clinically significant prostate cancer, family history was a significant predictor (OR, 6.32; 95\% Cl; 2.790-14.298; $p<0.001)$.

Conclusions: A family history of prostate cancer in Korean men was a significant factor for predicting prostate cancer. Moreover, significant differences in the aggressive features of the disease were identified between patients with and without a family history.

Keywords: Biopsy; History; Prostatic neoplasms

This is an Open Access article distributed under the terms of the Creative Commons Attribution Non-Commercial License (http://creativecommons.org/licenses/by-nc/4.0) which permits unrestricted non-commercial use, distribution, and reproduction in any medium, provided the original work is properly cited.

\section{INTRODUCTION}

Family history and family or personal history of highrisk germline mutations are included in the National Comprehensive Cancer Network (NCCN) guidelines for the early detection of prostate cancer [1]; however, it was not considered as a stronger factor than the serum prostatespecific antigen (PSA) level for the diagnosis of prostate cancer. Furthermore, prostate cancer in men with a family history is not more likely to be aggressive. However, these findings have been based on studies that were conducted in Western countries, and the conclusions drawn from the results may not apply to Asians.

Prostate cancer in Asian countries is more advanced and aggressive than that in Western countries [2-4], and this might result from differences in races. Family history and genes such as BRCA1, BRCA2, and ATM may help explain the differences of prostate cancer according to the races; however, studies about clinical features of hereditary or familial prostate cancer in Asian men are scarce.

Received: 8 April, 2019 • Accepted: 24 June, 2019

Corresponding Author: Kwang Suk Lee (iD https://orcid.org/0000-0002-7961-8393

Department of Urology, Gangnam Severance Hospital, Yonsei University College of Medicine, 211 Eonju-ro, Gangnam-gu, Seoul 06273, Korea

TEL: +82-2-2019-3470, FAX: +82-2-3462-8887, E-mail: winner0428@gmail.com 
Furthermore, the impact of family history on the diagnosis of prostate cancer among Asian men remains controversial [5,6]. In this study, we evaluated whether a positive family history of prostate cancer is associated with the diagnosis and aggressiveness of the prostate cancer among Korean men.

\section{MATERIALS AND METHODS}

\section{Study population and data collection}

This retrospective study was approved by the Gangnam Severance Hospital Institutional Review Board (approval number: 3-2016-0151), and informed consent was obtained from all individual participants included in the study. All procedures involving human participants were performed in accordance with the ethical standards of the institutional research committee and with the 1964 Declaration of Helsinki and subsequent amendments or comparable ethical standards. Six hundred and two patients who underwent a transrectal ultrasound-guided prostate biopsy from March 2015 to September 2017 were initially selected. The indication for prostate biopsy was persistent clinically suggestive findings of prostate cancer, such as an elevated PSA level $\geq 3.0 \mathrm{ng} / \mathrm{mL}$, steadily increasing PSA level, and abnormal results of a digital rectal examination. Patients $(n=10)$ who underwent confirmative prostate biopsy after treatment for previously diagnosed prostate cancer were excluded.

Patient demographics, including age, body mass index, the use of 5 $\alpha$-reductase inhibitors, PSA level, prostate volume, presence of previous prostate biopsy history, biopsy Gleason score, and clinical staging according to the 7th edition of the American Joint Committee on Cancer, were obtained
[7]. Magnetic resonance imaging and whole-body bone scans were routinely assessed in patients diagnosed with prostate cancer. The images were interpreted by radiology specialists in the urology department of our hospital, and the tumour pathology was determined by pathology specialists. Clinically significant prostate cancer was defined as a Gleason score $\geq 7$.

All patients who underwent prostate biopsy were asked whether they had a family history of prostate cancer. Information on family history was obtained via a selfadministered questionnaire at baseline. A positive family history was defined as having a father and/or one or more brothers with a diagnosis of prostate cancer. Men whose family history could not be determined, such as those with no brothers or whose father died early, were considered to have a negative family history.

\section{Statistical analysis}

Continuous variables are expressed as a median (interquartile range). Categorical variables are reported as the number of occurrences and frequency. The Mann-Whitney $\mathrm{U}$ test and the Pearson chi-square test were used to perform statistical comparisons of continuous and categorical variables, respectively. In the analysis for predicting the diagnosis of prostate cancer and clinically significant prostate cancer, multiple logistic regressions were used. All statistical comparisons were conducted with IBM SPSS Statistics version 23.0 (IBM Corp., Armonk, NY, USA). A p-value $<0.05$ was considered statistically significant.

Table 1. Baseline characteristics of the patients

\begin{tabular}{|c|c|c|c|c|}
\hline Characteristic & Total & Family history(-) & Family history(+) & p-value \\
\hline No. of patients & $602(100.0)$ & $561(93.2)$ & $41(6.8)$ & \\
\hline Age (y) & $68.3(62.1-74.0)$ & $68.4(62.2-74.2)$ & $64.0(60.8-70.4)$ & 0.032 \\
\hline PSA level (ng/mL) & $6.28(4.53-11.13)$ & $6.27(4.61-11.16)$ & $6.88(4.28-11.10)$ & 0.915 \\
\hline Prostate volume $\left(\mathrm{cm}^{3}\right)$ & $39.5(29.4-51.8)$ & $39.6(29.5-52.3)$ & $36.3(28.8-49.1)$ & 0.339 \\
\hline PSA density $\left(\mathrm{ng} / \mathrm{mL} / \mathrm{cm}^{3}\right)$ & $0.17(0.11-0.31)$ & $0.17(0.11-0.31)$ & $0.18(0.12-0.41)$ & 0.587 \\
\hline History of prostate biopsy (yes) & $118(19.6)$ & $107(19.1)$ & $11(26.8)$ & 0.228 \\
\hline Diagnosis of prostate cancer & $299(49.7)$ & $271(48.3)$ & $28(68.3)$ & 0.014 \\
\hline Gleason score $(n=299)$ & & & & 0.009 \\
\hline$\leq 6$ & $98(32.8)$ & $95(35.1)$ & $3(10.7)$ & \\
\hline$\geq 7$ & $201(67.2)$ & $176(64.9)$ & $25(89.3)$ & \\
\hline Clinical stage $(n=267)$ & & & & 0.812 \\
\hline$\leq \mathrm{cT} 2$ & $170(56.9)$ & $154(56.8)$ & $16(57.1)$ & \\
\hline$\geq \mathrm{cT} 3$ & $97(32.4)$ & $87(32.1)$ & $10(35.7)$ & \\
\hline
\end{tabular}

Data are presented as number (\%) or median (interquartile range). PSA, prostate-specific antigen. 


\section{RESULTS}

\section{Patient characteristics}

The baseline characteristics of the study patients are summarised in Table 1. Of 602 patients (median age, 68.3 years; median PSA level, $6.28 \mathrm{ng} / \mathrm{mL}$ ) included in this study, 299 (49.7\%) patients were diagnosed with prostate cancer. Of $41(6.8 \%)$ patients identified with a positive family history, 28 patients were diagnosed with prostate cancer. The median patient age, number of patients diagnosed with prostate cancer, and number of patients diagnosed with clinically significant prostate cancer were significantly higher in patients with family history of prostate cancer $(p=0.032$, $\mathrm{p}=0.014$, and $\mathrm{p}=0.009$, respectively).

\section{Association of a family history with the diagno- sis of prostate cancer}

Multivariate analysis was performed to investigate the predictors of patients diagnosed with prostate cancer (Table 2). Age (odds ratio [OR], 1.07; 95\% confidence interval [CI], 1.043-1.098; p<0.001), PSA level (OR, 1.16; 95\% CI, 1.105-1.210; $\mathrm{p}<0.001$ ), prostate volume (OR, 0.95; 95\% CI, 0.934-0.960; $\mathrm{p}<0.001$ ), and presence of a family history (OR, 2.99; 95\% CI, 1.330-6.704; $p=0.008$ ) were identified as significant predictors of prostate cancer diagnosis.

\section{Association of a family history with the diagno- sis of clinically significant prostate cancer}

Of the patients diagnosed with prostate cancer, 201 (67.2\%) patients were identified as having clinically significant prostate cancer. Multivariate analysis was performed to investigate the predictors of diagnosis of clinically significant prostate cancer (Table 3). Age (OR, 1.04; 95\% CI, 1.013-1.069; $\mathrm{p}=0.004)$, the PSA level (OR, 1.12; 95\% CI, 1.068-1.164; $\mathrm{p}<0.001$ ), prostate volume (OR, 0.95; 95\% CI, 0.935$0.968 ; \mathrm{p}<0.001)$, PSA density $\left(\geq 0.15 \mathrm{ng} / \mathrm{mL} / \mathrm{cm}^{3}\right)(\mathrm{OR}, 2.01 ; 95 \%$ CI, 1.098-3.685; $\mathrm{p}=0.024)$, and presence of a family history (OR, 6.32; 95\% CI, 2.790-14.298; p<0.001) were identified as significant predictors of clinically significant prostate cancer.

\section{DISCUSSION}

The impact of a family history of prostate cancer on the diagnosis and clinicopathologic outcomes of prostate cancer has been investigated in several studies [8-15]. Previous studies revealed that the heritability of prostate cancer carries a 2.1 to 25-fold increased risk of developing prostate cancer [13-15]. Moreover, the presence of a family history is associated with a higher potential risk of a diagnosis of prostate cancer at a younger age ( $\leq 65$ years) $(\mathrm{OR}, 4.3)$ [14]. Our study also showed that patients with familial history had significantly younger age. From this result and findings from other studies, we may infer that familial history of prostate cancer is related to age at diagnosis. The

Table 2. Results of univariate and multivariate analyses of the factors for predicting the diagnosis of prostate cancer

\begin{tabular}{|c|c|c|c|c|}
\hline & \multicolumn{2}{|c|}{ Univariate analysis } & \multicolumn{2}{|c|}{ Multivariate analysis } \\
\hline & OR $(95 \% \mathrm{Cl})$ & p-value & OR $(95 \% \mathrm{Cl})$ & p-value \\
\hline Age & $1.07(1.046-1.091)$ & $<0.001$ & $1.07(1.043-1.098)$ & $<0.001$ \\
\hline PSA level & $1.11(1.073-1.150)$ & $<0.001$ & $1.16(1.105-1.210)$ & $<0.001$ \\
\hline Prostate volume & $0.97(0.960-0.981)$ & $<0.001$ & $0.95(0.934-0.960)$ & $<0.001$ \\
\hline PSA density $\geq 0.15 \mathrm{ng} / \mathrm{mL} / \mathrm{cm}^{3}$ & $4.60(3.210-6.593)$ & $<0.001$ & $1.10(0.642-1.900)$ & 0.721 \\
\hline History of prostate biopsy & $0.61(0.405-0.918)$ & 0.018 & $0.65(0.396-1.050)$ & 0.078 \\
\hline Family history & $2.31(1.170-4.542)$ & 0.016 & $2.99(1.330-6.704)$ & 0.008 \\
\hline
\end{tabular}

$\mathrm{OR}$, odds ratio; $\mathrm{Cl}$, confidence interval; $\mathrm{PSA}$, prostate-specific antigen.

Table 3. Results of univariate and multivariate analyses of the factors for predicting the diagnosis of clinically significant prostate cancer

\begin{tabular}{|c|c|c|c|c|}
\hline & \multicolumn{2}{|c|}{ Univariate analysis } & \multicolumn{2}{|c|}{ Multivariate analysis } \\
\hline & OR $(95 \% \mathrm{CI})$ & p-value & OR $(95 \% \mathrm{CI})$ & p-value \\
\hline Age & $1.05(1.030-1.077)$ & $<0.001$ & $1.04(1.013-1.069)$ & 0.004 \\
\hline PSA level & $1.12(1.082-1.152)$ & $<0.001$ & $1.12(1.068-1.164)$ & $<0.001$ \\
\hline Prostate volume & $0.97(0.961-0.984)$ & $<0.001$ & $0.95(0.935-0.968)$ & $<0.001$ \\
\hline PSA density $\geq 0.15 \mathrm{ng} / \mathrm{mL} / \mathrm{cm}^{3}$ & $7.91(4.987-12.544)$ & $<0.001$ & $2.01(1.098-3.685)$ & 0.024 \\
\hline History of prostate biopsy & $0.56(0.352-0.889)$ & 0.014 & $0.68(0.387-1.189)$ & 0.175 \\
\hline Family history & $3.42(1.780-6.563)$ & $<0.001$ & $6.32(2.790-14.298)$ & $<0.001$ \\
\hline
\end{tabular}

$\mathrm{OR}$, odds ratio; $\mathrm{Cl}$, confidence interval; PSA, prostate-specific antigen. 
one possible reason would be that patients with a family history might have undergone PSA testing earlier than the general population due to the consciousness of their health of the prostate. However, there could be hereditary factors of prostate cancer and those with familial prostate cancer history would be susceptible to prostate cancer at younger age. We do not know the clear reason why those with family history of prostate cancer were younger, but it is certain that we should perform PSA screening for those with familial history of prostate cancer at younger age. Future studies would be needed to confirm the exact age for the initiation of PSA screening with familial prostate cancer history.

Several studies reported that men with a first-degree family history have a higher possibility of tumour detection with a low-grade Gleason score $(\leq 6)$. Azzouzi et al. [16] reported that cases of familial prostate cancer do not show any progression, as compared with sporadic cases. Raheem et al. [17] reported that patients with first-degree relatives who died of prostate cancer do not have an increased likelihood of high-risk or aggressive prostate cancer or shorter-term risk of biochemical recurrence compared to those who did not die of prostate cancer. No difference in prostate cancer mortality was observed in terms of family history [18]. Contrary to previous studies, our study demonstrated that family history of prostate cancer was a novel predictor for the diagnosis of the both prostate cancer and clinically significant prostate cancer (Gleason score $\geq 7$ ). Therefore, a positive family history was associated with aggressive features of the disease at diagnosis. However, our group previously reported that the presence of a family history was not identified as a prognostic factor of overall survival for prostate cancer among Korean population [19]. Additionally, no statistically significant differences were found in several parameters, including the Gleason score and pathologic stage, tumour volume, and positive surgical margin, between patients with and without a family history. Furthermore, family history had no prognostic effect on biochemical failure. However, our previous study confined the study population to those who have undergone radical prostatectomy [19]. Therefore, the prostate cancer was more aggressive in those group compared to the study population in this study and this might be the reason why the family history was reported as significant predictor of clinically significant prostate cancer with higher Gleason scores only in this study. Since previous study only confined to the patients who have undergone radical prostatectomy, we provided more clinically practical group of patients who have underwent transrectal ultrasound-guided prostate biopsy according to the indication. Therefore, we believe that patients with a family history of prostate cancer are diagnosed with high-grade prostate cancer, but worse survival cannot be presumed.

The impact of family history on the diagnosis of prostate cancer was mainly conducted in Western countries. To the best of our knowledge, published reports in Asians are scarce and remain controversial. Nagata et al. [5] reported no association between family history and prostate cancer risk. However, a recent study reported that family history is strongly associated with an increased risk for prostate cancer [6]. This study, which analysed more patients than previous studies, showed that the presence of a family history of prostate cancer was a significant risk factor of prostate cancer diagnosis in Korean populations. Prostate cancer is more advanced and aggressive in Asian countries than in Western countries [2-4]. No data about the epidemiology or ethnicity, particularly the clinical features of hereditary or familial prostate cancer in Asian men, are available. We found that the proportion of clinically significant prostate cancer (Gleason score 27 ) was higher in men with a family history of prostate cancer than in men without a family history. The NCCN guidelines state that BRACA1/2 pathogenic mutation carriers are associated with an increased risk of prostate cancer before age 65 years, and prostate cancer in men with germline BRCA2 mutations occurs earlier and is more likely to be associated with prostate cancer mortality [1]. In order to clarify the epidemiology of prostate cancer in Korean men and explain our findings, we plan to investigate the genetic factors, such as gene mutations and chromosomal, and gene or single nucleotide polymorphisms.

This is the largest study to determine that family history is a predicting factor for prostate cancer diagnosis in Korean population. Moreover, this study is the first one in that men with a family history of prostate cancer were younger and had a higher Gleason score than those without a family history at the time of diagnosis. Despite these strengths, this study has several limitations. First, the sample size of our enrolled patients was small, which imposed limitations on the statistical power of the results. However, it was sufficient to evaluate the effect of family history on the diagnosis of prostate cancer among Korean men. This finding can be verified in future large-scale studies. Second, the stratification according to the definition of clinically significant prostate cancer lacked standardisation; thus, a different data collection method could yield different results. Despite these limitations, further large, population-based studies are warranted to elucidate the epidemiology of a 
family history of prostate cancer. We are designing future studies to identify the predictive value of a family history of prostate cancer by investigating genetic characteristics.

\section{CONCLUSIONS}

This study demonstrated the importance of family history of prostate cancer among Korean populations in predicting prostate cancer. There were statistically significant differences not only in detection of prostate cancer but also in the aggressiveness of the disease between patients with and without a family history of prostate cancer.

\section{CONFLICTS OF INTEREST}

The authors have nothing to disclose.

\section{REFERENCES}

1. Carroll PH, Mohler JL. NCCN Guidelines updates: Prostate Cancer and Prostate Cancer Early detection. J Natl Compr Canc Netw 2018;16(5S):620-3.

2. Lee DH, Lee SH, Rha KH, Choi IY, Lee JY, Kim SW, et al. The establishment of K-CaP (the multicenter Korean Prostate Cancer Database). Korean J Urol 2013;54:229-33.

3. Li XG, Zhang DX, Cui XG, Xu DF, Hong Y, Li Y, et al. Evaluating the oncologic outcomes in 152 patients undergoing extraperitoneal laparoscopic radical prostatectomy. Chin Med J (Engl) 2012;125:1529-35.

4. Egawa S, Suyama K, Arai Y, Tsukayama C, Matsumoto K, Kuwao S, et al. Treatment outcome by risk group after radical prostatectomy in Japanese men. Int J Urol 2001;8:295-300.

5. Nagata Y, Sonoda T, Mori M, Miyanaga N, Okumura K, Goto K, et al. Dietary isoflavones may protect against prostate cancer in Japanese men. J Nutr 2007;137:1974-9.

6. Bashir MN, Ahmad MR, Malik A. Risk factors of prostate cancer: a case-control study in Faisalabad, Pakistan. Asian Pac J Cancer Prev 2014;15:10237-40.

7. Edge SB, Compton CC. The American Joint Committee on Cancer: the 7th edition of the AJCC cancer staging manual and the future of TNM. Ann Surg Oncol 2010;17:1471-4.

8. Aprikian AG, Bazinet M, Plante M, Meshref A, Trudel C,
Aronson S, et al. Family history and the risk of prostatic carcinoma in a high risk group of urological patients. J Urol 1995;154(2 Pt 1):404-6.

9. Cussenot O, Valeri A, Meria P, Berthon P, Fournier G, Teillac $\mathrm{P}$, et al. [Genetic aspects in cancers of the prostate]. Pathol Biol (Paris) 1996;44:737-43. French.

10. Gianferrari L, Arrigoni G, Cresseri A, Lovati G, Morganti G. [Genetic and clinico-statistical research on neoplasms of the prostate]. Acta Genet Med Gemellol (Roma) 1956;5:224-33. Italian.

11. Roemeling S, Roobol MJ, de Vries SH, Gosselaar C, van der Kwast TH, Schröder FH. Prevalence, treatment modalities and prognosis of familial prostate cancer in a screened population. J Urol 2006;175:1332-6.

12. Morrison BF, Aiken WD, Mayhew R, Gordon Y, Odedina FT. Prostate cancer knowledge, prevention, and screening behaviors in Jamaican men. J Cancer Educ 2017;32:352-6.

13. Lichtenstein P, Holm NV, Verkasalo PK, Iliadou A, Kaprio J, Koskenvuo M, et al. Environmental and heritable factors in the causation of cancer--analyses of cohorts of twins from Sweden, Denmark, and Finland. N Engl J Med 2000;343:78-85.

14. Johns LE, Houlston RS. A systematic review and meta-analysis of familial prostate cancer risk. BJU Int 2003;91:789-94.

15. Bruner DW, Moore D, Parlanti A, Dorgan J, Engstrom P. Relative risk of prostate cancer for men with affected relatives: systematic review and meta-analysis. Int J Cancer 2003;107:797803.

16. Azzouzi AR, Valeri A, Cormier L, Fournier G, Mangin P, Cussenot $\mathrm{O}$. Familial prostate cancer cases before and after radical prostatectomy do not show any aggressiveness compared with sporadic cases. Urology 2003;61:1193-7.

17. Raheem OA, Cohen SA, Parsons JK, Palazzi KL, Kane CJ. A family history of lethal prostate cancer and risk of aggressive prostate cancer in patients undergoing radical prostatectomy. Sci Rep 2015;5:10544.

18. Saarimäki L, Tammela TL, Määttänen L, Taari K, Kujala PM, Raitanen J, et al. Family history in the Finnish Prostate Cancer Screening Trial. Int J Cancer 2015;136:2172-7.

19. Lee KS, Koo KC, Chung BH. The impact of a family history of prostate cancer on the prognosis and features of the disease in Korea: results from a cross-sectional longitudinal pilot study. Int Urol Nephrol 2017;49:2119-25. 